\title{
Imigração, refúgio e saúde: perspectivas de análise sociocultural
}

\section{Immigration, refuge and health: sociocultural analysis in perspective}

\author{
Denise Martin \\ Universidade Católica de Santos. Cátedra Sérgio Vieira de Mello. \\ Santos, SP, Brasil. \\ E-mail: demartinळunisantos.br
}

\section{Alejandro Goldberg}

Instituto Universitário de Lisboa. Centro de Investigação e Estudos de Sociologia. Lisboa, Portugal.

E-mail: alejandro.goldbergøgmail.com

\section{Cássio Silveira}

Faculdade de Ciências Médicas da Santa Casa de São Paulo. Departamento de Saúde Coletiva. São Paulo, SP, Brasil.

E-mail: cassio@cealag.com.br

\section{Correspondência}

Cássio Silveira

Faculdade de Ciências Médicas da Santa Casa de São Paulo, Departamento de Saúde Coletiva. Rua Cesário Mota Junior, 6I, $5^{\circ}$ andar. São Paulo, SP, Brasil. CEP OI221-020.

\section{Resumo}

Os recentes processos migratórios internacionais ocorridos no Brasil se apresentam como um campo de estudo para as ciências sociais e humanas em saúde. Este artigo tem como objetivo refletir sobre os processos de inclusão de imigrantes e refugiados pelas instituições de saúde, considerando o campo de debates das ciências sociais e humanas em Saúde e o comprometimento dessa área com os direitos humanos. Inicialmente, são apresentadas características contemporâneas das migrações internacionais, incluindo a situação brasileira. Em seguida, são descritas algumas pesquisas e práticas sobre concepções de saúde, doenças e cuidados com imigrantes e, por fim, propomos um debate acerca de alguns conceitos antropológicos que podem contribuir para uma abordagem menos estereotipada dos processos de inclusão nas instituições de saúde nacionais. Pretendemos apresentar uma perspectiva das ciências sociais e humanas em saúde em um horizonte teórico articulado com práticas em saúde que, de certa forma, podem contribuir para a formulação de conceitos, explicações e orientações no plano das políticas públicas com essas populações.

Palavras-chave: Processos Migratórios Internacionais; Imigrantes; Refugiados; Saúde; Ciências Sociais e Humanas em Saúde. 


\section{Introdução}

The international migratory processes that are recently occurring in Brazil are a field of study for Health Social and Human Sciences. This article aims to reflect on immigrants and refugees processes of inclusion by health institutions, considering the discussion possibilities of Health Social and Human Sciences and the commitment of this area to Human Rights. Initially, contemporary characteristics of international migrations are presented, including the Brazilian situation. Some researches and practices about conceptions of health, illness and care with immigrants are described below, and, finally, we propose a debate on some anthropological concepts that can contribute to create a less stereotyped approach in the processes of inclusion in national health institutions. We intend to present a perspective of Health Social and Human Sciences within a theoretical horizon that is articulated with health practices that can somehow contribute to the formulation of concepts, explanations and guidelines in public policies to these populations. Keywords: Immigration; International Migration Processes; Refugees; Health; Health Social Sciences.
Os estudos sobre os processos migratórios e a saúde dos imigrantes têm ampliado sua visibilidade em espaços importantes de comunicação em saúde coletiva por meio de publicações acadêmicas já tradicionais no campo ou de eventos científicos no Brasil e no Cone Sul. Tal amplitude expressa mais que um crescimento do número de eventos e comunicações que delimitam a sua extensão. Demonstra a construção de um conjunto de problemas formulados em torno da questão migratória internacional no Cone Sul, seus desdobramentos e avanços na produção de conhecimentos empíricos e as articulações teórico-conceituais e metodológicas no campo interdisciplinar da saúde coletiva (Goldberg; Martin; Silveira, 2015; Mota; Marinho; Silveira, 2014).

A proposta deste texto é refletir sobre os processos de inclusão de imigrantes e refugiados pelas instituições de saúde, considerando o campo de debates das ciências sociais e humanas em saúde e o comprometimento dessa área com os direitos humanos. A primeira parte do texto apresenta algumas tendências contemporâneas no campo das migrações internacionais, incluindo uma descrição do atual quadro migratório internacional no Brasil. Em seguida, abordamos algumas experiências no campo da saúde coletiva, especialmente sobre pesquisas e práticas que envolvem o debate sobre concepções de saúde, doença e cuidados com esses grupos de imigrantes.

Por fim, propomos o debate de alguns conceitos antropológicos que podem contribuir para uma abordagem menos estereotipada nos processos de inclusão nas instituições de saúde nacionais. Pretendemos, assim, apresentar uma perspectiva das ciências sociais e humanas em saúde em um horizonte teórico articulado com práticas em saúde que, de certa forma, podem contribuir para a formulação de conceitos, explicações e orientações no plano das políticas públicas com essas populações.

\section{O Brasil no contexto das migrações internacionais}

A situação migratória coloca uma série de questionamentos acerca da saúde das pessoas que 
vivenciam múltiplas situações de deslocamento. Um quadro conceitual das migrações expõe cenários diferenciados nos processos migratórios, apresentando conceitos variados que explicitam os sentidos da imigração, da emigração e dos refugiados. Esses processos, originados em causas econômicas, políticas e ambientais, impulsionam ao deslocamento transnacional indivíduos e famílias que acabam por se expor a múltiplas fragilidades durante os percursos de trânsito e nas situações vivenciadas nas experiências concretas de vida nas sociedades de recepção (Zimmerman; Kiss; Hossain, 2011).

Os processos migratórios contemporâneos são um fenômeno global e vêm adquirindo conformações específicas nos continentes. Por exemplo, o Brasil neste século fez parte desse contexto ao receber imigrantes de vários outros países e em situações bastante diferenciadas. Constitui-se, portanto, como componente nos novos cenários de mobilidade humana ocorridos principalmente na América do Sul e que têm evidenciado reconfigurações nas características da mobilidade humana no continente, alterando a circulação de grupos de imigrantes em curtos espaços temporais.

No mapa das migrações internacionais para o Brasil, os haitianos ganharam destaque nas mídias, por um lado, pelo volume dos deslocamentos vivenciados por homens e mulheres em busca de trabalho em terras distantes, longe das trágicas consequências de um terremoto de largas proporções; por outro lado, pelo atrativo gerado a partir de um acordo bilateral entre os governos do Haiti e Brasil - mediado pela Organização das Nações Unidas (ONU) -, criando, assim, meios facilitadores para a integração desses imigrantes pelo fornecimento de registro no Cadastro Nacional de Pessoas Físicas (CPF), o que permitiu a inserção mais ágil no mercado de trabalho, apesar dos percalços e iniquidades, já amplamente divulgados, sofridos por esse grupo de imigrantes (Bogus; Fabiano, 2015; Granada et al., 2017; Leão et al., 2017; Santos, 2016; Silva, 2017).

A circulação de sul-americanos, em particular bolivianos e paraguaios, presentes principalmente na região sudeste do país, constitui objeto importante nas análises migratórias do Cone Sul, principalmente por delimitar no mapa das migrações internacionais a relação entre Sul e Sul (Baeninger, 2012; Silva, 2005). Estudos acerca desses grupos têm indicado o trânsito intenso de homens e mulheres e seus familiares pelas fronteiras terrestres em busca de trabalho e, portanto, melhores condições de vida. Tal movimento impõe a essas pessoas variadas situações de risco à saúde (Goldberg; Silveira, 2013; Goldberg; Martin; Silveira, 2015).

A movimentação de grupos de imigrantes nos países que compõem o Cone Sul, em particular os bolivianos (Aguiar; Mota, 2014; Baeninger, 2012; Sala; Carvalho, 2008; Silva, 2005) e também os grupos vindos da América Central, da África, da Ásia, da Europa e do Oriente Médio (Cavalcanti; Oliveira; Tonhati, 2015; Mota; Marinho; Silveira, 2014; Patarra, 2005), tem motivado debates em busca da compreensão desses fluxos migratórios internacionais em suas conexões com cidades e/ou regiões metropolitanas específicas. 0 caso da região metropolitana de São Paulo evidencia a circularidade dos caminhos trilhados pelos imigrantes. A busca por ramos específicos da produção, como é o caso dos bolivianos trabalhadores na indústria de confecção, ou mesmo o trânsito de haitianos que migram internamente em busca de alternativas que emergem em meio às rápidas transformações ocorridas na diminuição do controle e vigilância sobre a exploração do trabalho nos últimos tempos ${ }^{1}$. Africanos subsaarianos, representados por senegaleses, congoleses, angolanos, entre outros, perfazem caminhos entre as macrorregiões Sudeste e Sul do país, conectando-se com países vizinhos, como é o caso dos senegaleses em suas conexões com a região metropolitana da cidade de Buenos Aires, Argentina (Goldberg; Sow, 2017).

Mais recentemente, venezuelanos passaram a se movimentar pelas fronteiras da região norte do Brasil, constituindo mais um importante movimento de deslocamento de pessoas em rota de fuga de uma grave crise econômica e política pela qual passa o país. Nesse processo migratório, ganhou destaque o deslocamento de algumas centenas de 
membros da etnia indígena Warao, que ocuparam espaços públicos (edificações abandonadas, ruas e baixos de viadutos) nas cidades de Boa Vista/RR e Manaus/AM, mobilizando organizações públicas. Impôs-se um desafio no processo de formação de um espaço de convivência permeado, de um lado, por ações públicas de cuidados emergenciais que evidenciam as dificuldades de caráter intercultural; de outro, por manifestações de resistência e/ou solidariedade com esse grupo marcado pela pobreza e indigência no contexto da sociedade brasileira (Simões et al., 2017).

Os refugiados compõem parte do mapa das migrações internacionais no Brasil. O país soma cerca de nove mil emissões de concessão de refúgio, principalmente a grupos de sírios, angolanos e colombianos. Os pedidos de refúgio somam mais de vinte mil solicitações formais no país (Brasil, 2017).

A lei brasileira atual sobre o refúgio, nº 9.474, de 22 de julho de 1997, é assim definida:

Artigo $1^{\circ}$ - Será reconhecido como refugiado todo indivíduo que: I - devido a fundados temores de perseguição por motivos de raça, religião, nacionalidade, grupo social ou opiniões políticas, encontre-se fora de seu país de nacionalidade e não possa ou não queira acolher-se à proteção de tal país; II - não tendo nacionalidade e estando fora do país onde antes teve a residência habitual, não possa ou não queira a ele regressar, em função das circunstâncias descritas no inciso anterior; III - devido à grave e generalizada violação de direitos humanos, é obrigado a deixar seu país de nacionalidade para buscar refúgio em outro país. (Brasil, 1997)

O status de refugiado é uma condição jurídica concedida pelo governo brasileiro a partir do Comitê Nacional para os Refugiados (Conare), que é formado por órgãos governamentais, instituições representantes da sociedade civil e organizações internacionais para refugiados, como o Alto Comissariado das Nações Unidas para Refugiados (ACNUR). Pacífico e Gaudêncio (2014) chamam a atenção para as consequências das alterações ambientais para a mobilidade humana, os chamados deslocados ambientais, que necessitam sair de suas fronteiras, embora não exista perseguição, como exigido pelo estatuto do refúgio. Todavia, há ausência de reconhecimento legal e proteção jurídica específica para essa categoria de pessoas.

Europeus de países como Itália, Portugal e Espanha ainda constituem grupos numericamente representativos no país, formam redes de conexões mais seguras e, portanto, com forte inserção social (Oliveira, 2013). Por outro lado, os haitianos que circulam em grandes cidades do Sudeste e do CentroOeste, deslocando-se, também, em direção ao Sul - às vezes redirecionando sua trajetória ao México e aos Estados Unidos -, têm demonstrado as fragilidades concernentes a processos migratórios de grupos sociais menos favorecidos economicamente ou deslocamentos humanos decorrentes de áreas de conflito e/ou transformações ambientais (Granada et al., 2017; Leão et al., 2017; Santos, 2016).

Pode-se ressaltar a complexidade do quadro migratório internacional no Brasil caracterizado, primeiramente, pela heterogeneidade sociocultural que delineia múltiplas trajetórias internas e pelas diferenças postas pelos grupos migratórios no tocante às suas condições de vida em seus países de origem e, portanto, dos processos migratórios. Os dados demográficos sobre migrações internacionais no Brasil demonstram que no começo deste século a entrada de novos contingentes de estrangeiros diminuiu quando comparada aos ocorridos no passado histórico brasileiro. Dados do Censo Demográfico de 1991 registraram uma população estrangeira de 606.631 pessoas (o,41\% da população residente no país) e dados de 2000 registraram 683.380 pessoas (o,40\% de seu total populacional). Boa parte (cerca de $40 \%$ ) teve origem nos países do Mercosul Ampliado (Argentina, Paraguai, Uruguai, Chile, Bolívia e Peru) e, em menor parte, estão os imigrantes europeus (20\%), asiáticos $(12,5 \%)$ e da América do Norte (9,1\%) (Patarra, 2005).

Na segunda década deste século, dados coletados e consolidados pelo Observatório de Migrações Internacionais (OBMIGRA) demonstram crescimento de $126 \%$ de trabalhadores imigrantes no mercado formal de trabalho. Os haitianos destacam-se pelo intenso crescimento anual do fluxo migratório no período de 2011 a 2014 (Cavalcanti; Oliveira; Tonhati, 2015). O Censo Demográfico de 2010, por sua vez, 
evidencia o incremento no volume da imigração internacional no Brasil. Entraram no país 268.486 pessoas, contudo, destas, $65 \%$ eram nascidas no Brasil, ou seja, retornaram após emigrarem para os Estados Unidos, Japão, Portugal e Paraguai, entre outros países (Oliveira, 2013).

\section{Migrações internacionais e saúde dos imigrantes}

De maneira geral, o Brasil não se destaca no quadro mundial das migrações internacionais. Os fluxos migratórios internacionais que por aqui ocorreram nos últimos trinta anos ganharam destaque por sua importância na economia nacional. Um dos aspectos observados é a sua estrutura etária composta predominantemente por jovens adultos, o que indica o papel essencial da migração laboral e também a chegada de mão de obra qualificada. Segundo Oliveira (2013), no Brasil os estrangeiros representavam o, $8 \%$ da população residente no país, fato que indica uma inexpressiva participação no contexto mundial migratório.

Ainda assim, as descrições dos casos não podem prescindir de análises mais abrangentes e que possibilitem a compreensão das migrações internacionais como questão social. Uma moldura teórico-compreensiva permite apreender as migrações internacionais - principalmente o caso brasileiro - como um movimento impulsionado pelos fluxos de capitais orientados pela lógica de um capitalismo que, em fins do século XX e início do século XXI, ultrapassou as fronteiras político-administrativas e organizou relações de trabalho fundadas na precarização com vistas à diminuição do custo da produção, no contexto da circulação transnacional de produtos. A aceleração das migrações pelas fronteiras, caso típico dos movimentos em países do Cone Sul - Bolívia-São Paulo, Bolívia-Buenos Aires, Paraguai-São Paulo e Paraguai-Buenos Aires -, tem demonstrado que as circulações transnacionais trespassam fronteiras, abrem oportunidades de trabalho, constroem redes e, simultaneamente, expõem os sujeitos imigrantes a vulnerabilidades e riscos (Rizek; Georges; Silva, 2010; Sassen, 1988; Silva, 2005).
Mesmo que a não caracterização do Brasil como país de imigração e emigração seja evidenciada pelos dados demográficos, o conjunto de problemas relacionados à saúde dos imigrantes permanece mobilizando políticas, serviços e setor acadêmico. Os processos sociais e contextos sociopolíticos pelos quais os imigrantes percorrem caminhos nem sempre são favoráveis à sua saúde. Análises cuidadosas sobre os modos de vida, as concepções sobre adoecimento, os diversos modos de lidar com a saúde e a doença, as intercorrências de adoecimento no processo migratório, assim como as análises dos sistemas de saúde que recebem imigrantes, ganham destaque no país, constituindo uma base à formulação de preocupações teórico-conceituais e práticas que abrem perspectivas à compreensão do processo saúdedoença-cuidados entre os imigrantes e refugiados.

Casos específicos de ações inclusivas em saúde, dentro do Sistema Único de Saúde (SUS) no município de São Paulo, ilustram a mobilização de agentes comunitários de saúde em vista dos imigrantes. A inovação ocorreu pela ação de contratação de agentes comunitários oriundos dos grupos de imigrantes dos seguintes países: Bolívia, África do Sul, Congo, Cuba, Espanha, Nigéria, Portugal e Serra Leoa (Aguiar; Mota, 2014; Boletim CEInfo, 2015; Goldberg; Silveira, 2013). Em 2016, as ações promovidas em São Paulo conformaram a Lei Municipal para Imigrantes e Refugiados, consolidando um conjunto de intenções e experiências já desenvolvidas com essa população. A legislação permitiu criar o Conselho Municipal de Imigrantes e também o Fórum Permanente de Imigrantes (São Paulo, 2016; Steffens; Martins, 2016).

Pesquisas realizadas sobre os imigrantes no país já permitem compor um quadro descritivo e analítico sobre as condições de saúde e as políticas voltadas às necessidades desses grupos. Silva (2017) introduz ao debate sobre as imigrações na cidade de Uberlândia/MG uma análise sobre as políticas de trabalho e saúde contemporânea, as formas de controle sobre o trabalho e os cuidados em saúde dos trabalhadores. Evidencia naquele contexto a necessidade do enfrentamento das adversidades geradas dentro do processo transnacional de trabalhadores (por exemplo, uma 
leva de trabalhadores vindos de Bangladesh para a indústria frigorífica).

Por outro lado, análises de experiências de inclusão em serviços de atenção primária evidenciam a complexidade das ações de cadastramento e de acompanhamento dos sujeitos imigrantes. Por exemplo, em Chapecó/SC, Risson (2016) expõe a necessidade do enfrentamento de ações preconceituosas nos serviços de saúde, incluindo atos de racismo e inclusão precária no sistema de saúde. Por outro lado, Aguiar e Mota (2014) e Foster (2017) mostram experiências de inclusão no contexto da atenção primária em saúde por meio da construção de estratégias de cuidado dentro da acelerada dinâmica dos processos migratórios na área central da cidade de São Paulo. Na cidade de Cuiabá/MT, Leão et al. (2017) descrevem a situação de saúde de trabalhadores haitianos e expõem a precária condição social, econômica e laboral desse grupo de imigrantes na capital mato-grossense.

As iniciativas anteriormente descritas apontam para mobilizações teóricas e práticas perante os desafios apresentados pelos diferentes contextos vividos por populações de imigrantes. Cabe apontar, ainda, o importante fato ocorrido em 2017 da aprovação da nova Lei de Migração, ainda que ressalvados os vetos presidenciais (Brasil, 2017). Dada a complexidade dos processos migratórios anteriormente expostos, é importante discutir alguns aspectos teórico-conceituais que podem implicar na compreensão desse fenômeno. As intervenções com esses grupos de pessoas, na condição de imigrantes ou de refugiados, por meio de políticas públicas ou em práticas nos serviços de saúde, demandam algumas especificidades que serão discutidas a seguir.

\section{Imigração, diversidade sociocultural e saúde}

Malkki (1996) e Sargent e Larchanché (2011) mostram que os imigrantes podem ser considerados ora como vítimas, ora como heróis; podem ser vistos como pessoas que fizeram algo errado em seu país (no caso dos refugiados); podem trazer doenças; podem aumentar os riscos de problemas sociais e econômicos. Além desses aspectos, remetem frequentemente à questão das diferenças culturais, seja pela língua falada, pelas vestimentas, pelos códigos de educação e conduta, pela forma como tratam as crianças etc. De alguma forma, os imigrantes (aqui incluídos os refugiados) deixam evidente que compartilham de outros modos de ver e viver o mundo. Assim, a cultura, definida geralmente de uma maneira superficial e estereotipada, é imediatamente implicada nas explicações, justificativas e sentimentos em relação a essas pessoas.

Fassin (2012) faz uma interessante provocação sobre a maneira como os problemas de saúde associados aos imigrantes são associados a questões culturais, obscurecendo relações sociais, econômicas e de poder. O autor cita o exemplo da epidemia de saturnismo infantil ocorrida no final dos anos 1990 na França. Em 1981, os dados epidemiológicos traziam somente 10 relatos da doença em 25 anos e, em 1999, havia 85 mil crianças notificadas, sendo que $99 \%$ delas eram de origem africana. A compreensão do fenômeno envolveu assistentes sociais, toxicologistas, clínicos gerais de organizações não governamentais (ONG), universidades, assim como modificação dos contornos clínicos da doença (diminuição no nível de plumbemia), acarretando aumento da contaminação. A intoxicação por chumbo compromete a capacidade de aprendizagem e desempenho escolar. Adificuldade de identificar e tratar o problema ocorria também porque outros fatores não biológicos interferem nas competências cognitivas.

Fassin (2012) chama a atenção para o fato de que as explicações correntes sobre o fenômeno remetiam a práticas culturais particulares a essas famílias: por serem cuidados por curadores tradicionais muçulmanos; pelos produtos de maquiagem que as mulheres utilizavam; pela prática de geofagia. Ou seja, as crianças estavam contaminadas por chumbo e a justificativa para a doença estava nas práticas culturais específicas dessas populações, no caso, imigrantes africanos. Todavia, o autor propõe que, para entender por que as crianças estavam adoecendo, é necessário considerar as políticas migratórias em curso na França desde os anos 1970, que se tornaram cada vez mais restritivas quanto à imigração por razões de trabalho. Nesse sentido, 
os imigrantes, cada vez mais frágeis econômica e juridicamente, moravam nos apartamentos mais antigos e insalubres, em situação de clandestinidade. Nesses locais, as paredes eram pintadas com tintas à base de chumbo, proibidas desde 1948. Dessa forma, a contaminação das crianças estava ligada ao ambiente local, expondo as desigualdades sociais entre imigrantes.

Esse caso, relatado por Fassin (2012), evidencia as implicações políticas, epidemiológicas, clínicas e culturais envolvidas na compreensão de uma doença associada a imigrantes, no caso indesejados. Além disso, aponta para os problemas de uma explicação fundamentada em uma noção de cultura equivocada, associada ao exotismo, contribuindo para uma visão estereotipada, reducionista e discriminatória dos imigrantes. 0 conceito de cultura é complexo e polissêmico, podendo subverter a compreensão dos processos migratórios. Todavia, não pode ser ignorado, impondo novamente desafios para intervenções no campo da saúde.

As análises da inclusão de migrantes internacionais pelos sistemas oficiais de saúde mostram que boa parte dos casos ocorre sem que os sistemas de referência e os códigos próprios às sociedades de origem, incluindo todas as tradições e os valores carregados por indivíduos e famílias no processo migratório, sejam colocados em diálogo dentro do sistema receptor (Goldberg; Martin; Silveira, 2015). Colocado esse desafio, é necessário problematizá-lo. Considerando a complexidade e diversidade de referências teóricas envolvidas no debate sobre o conceito de cultura, optamos neste texto por trabalhar com o conceito de interculturalidade de Menéndez (2016). Segundo esse autor, o conceito de interculturalidade pode ser útil para abordar as relações entre imigrantes e o SUS. Os processos interculturais existem sempre que temos sociedades em contato, sendo permanentes e históricos e estão presentes nos processos de saúde, doença, atenção e prevenção (s/e/a-p), como chamado pelo autor.

Assim, como pensar, por exemplo, as incursões de congoleses em situação de refúgio no SUS? A partir de que referências buscam aliviar o seu sofrimento? O que é identificado como doença que merece atenção de profissionais de saúde? Quais profissionais são valorizados e quais são ignorados? Fora do SUS, como cuidam de sua saúde? Existe reconhecimento de sofrimentos que possam ser tratados dentro do nosso modelo de atenção à saúde mental? Estas, entre muitas outras, são questões que remetem aos desafios do cuidado em saúde das populações de imigrantes e de refugiados e para os quais apresentaremos algumas possibilidades teóricas para ajudar na sua compreensão.

Um primeiro aspecto a ressaltar, evidenciado por trabalhadores da saúde, é o perigo da generalização quanto à naturalidade: "os bolivianos”, “os congoleses", “os chineses”, “os sírios” etc. A redução da nacionalidade ao local de nascimento implica em problemas epistemológicos importantes, como o nacionalismo metodológico, que, de maneira sucinta, trata as sociedades nacionais como limitadas e naturalizadas (Peirano, 2004; Wimmer; Schiller, 2002). Todavia, há outras questões envolvidas no contato com populações imigrantes. Menéndez (2016) propõe uma crítica à forma como funcionários, profissionais e intelectuais promoveram a interculturalidade em saúde no México, que pode contribuir para pensar os desafios dos processos de saúde, doença, cuidados e atenção entre imigrantes no Brasil. Segundo esse autor, é correto reconhecer e trabalhar com os aspectos culturais, mostrando a diferença dos usos e costumes, nas cosmovisões e formas de vida originais. Todavia, é importante também incluir as desigualdades socioeconômicas e de poder.

No caso dos congoleses em situação de refúgio, estudados por Haydu (2017), a maioria dos participantes da pesquisa eram homens, com nível superior de estudo, nascidos em diferentes partes do país e, portanto, com diferentes exposições ao contexto de guerra. Eles se definiram quanto à opção religiosa pelo protestantismo, pelo catolicismo ou pelo islamismo, sendo alguns ateus. Chegando ao Brasil e recebendo o status de refugiado, são enquadrados na categoria "refugiados congoleses". A categoria jurídica parece englobar a concepção de pessoa (Mauss, 1974). Menéndez (2016) chama a atenção para o fato de que é necessário considerar também as diferenças em termos de religião, de gênero, adesão política, grau de escolaridade, grupos 
de idade ou de poder. Atores sociais não devem ser considerados homogêneos e monolíticos.

Além disso, o autor critica alguns autores que consideram as cosmovisões indígenas e a "ocidental", em relação oposta e incompatível, ressaltando também que há diferenças cruciais entre os grupos étnicos entre si. Os termos "Ocidente" e "Oriente" constituem construções ideológicas que não correspondem às diversidades, oposições e conflitos existentes entre os atores sociais. Transpondo para o caso dos imigrantes e refugiados, a ideia de um "nós" homogêneo pertencente à sociedade nacional, com cosmovisão ocidental, opondo-se aos "outros”, estrangeiros, também é um equívoco que, de certa forma, esconde relações de poder e desigualdades sociais.

No contexto dos serviços de saúde, é importante refletir sobre a maneira como esses imigrantes estão sendo tratados. As concepções dos profissionais de saúde se fundamentam no modelo biomédico (mas não exclusivamente nele) e, em situação de contato intercultural, opõem-se a um "outro". Vale dizer que ambos se enxergam de maneira imprecisa. Oliveira (200o) mostra como grupos de migrantes oferecem uma oportunidade privilegiada para o estudo das formas de interação na articulação entre identidade, etnicidade e nacionalidade. Há um valor estratégico para uma investigação que pretenda ser capaz de elucidar os mecanismos de identificação pelos outros, tanto quanto os de autoidentificação, embora esta seja reflexo daquela, sugere o autor. Não pretendemos nos deter nesse aspecto, somente ressaltar que o fenômeno sociocultural da identidade deve ser considerado no contato intercultural, com todas as ressalvas anteriormente citadas.

Ainda problematizando as relações interculturais no contexto do atendimento a imigrantes e refugiados, é importante também reconhecer que os grupos sociais não devem ser caracterizados somente pelo aspecto da permanência, ou seja, excluindo as possibilidades de mudanças socioculturais. Menéndez (2016) chama a atenção para a dimensão da mudança e que grupos étnicos funcionam tanto em relações de solidariedade e cooperação quanto conflito e violência, além do racismo presente nas relações sociais. Haydu (2017) evidencia o racismo sofrido por congoleses em situação de refúgio na cidade de São Paulo, identificados como "negros africanos".
Como mostrado anteriormente, os imigrantes e refugiados, no Brasil, estão tendo acesso ao SUS, seja por meio da estratégia Saúde da Família ou das unidades básicas de saúde (UBS), o que representa um grande avanço nos processos de inclusão. Segundo Menéndez (2016), essa expansão dos processos de inclusão dentro dos sistemas oficiais de saúde envolve tanto o sistema oficial estruturado predominantemente em bases técnico-científicas da biomedicina como grupos socioculturais com distintas tradições e práticas de saúde. 0 autor chama de modelos de atenção, na perspectiva antropológica, não somente as atividades biomédicas, mas todas as que se relacionam com a atenção aos sofrimentos, buscando prevenir, tratar, controlar, aliviar ou curar. Sugere também que é importante compreender as atividades diagnósticas exercidas pelos sujeitos e pelos grupos domésticos, denominadas por Menéndez (2003) de autoatenção, embasada na capacidade de agência dos sujeitos e microgrupos. Essas questões podem ser consideradas no contexto das relações entre profissionais de saúde e imigrantes ou refugiados. Todavia, expõem também a complexidade envolvida nesses cenários, em que o enfoque relacional e histórico é fundamental, como ressalta o autor. Por fim, Menéndez (2016) propõe que se busque nas relações interculturais também as similitudes e não somente as diferenças, que muitas vezes são as que se apresentam mais evidentes.

\section{Considerações finais}

Neste texto, buscamos expor parte da complexidade dos processos migratórios internacionais e seus impactos na sociedade brasileira. A apresentação de alguns temas já desenvolvidos em pesquisas e práticas no campo da saúde permitiu demonstrar a potência desse tema e a pluralidade de aspectos teóricos e metodológicos que requerem investigações aprofundadas. Ainda que os processos migratórios internacionais no Brasil sejam limitados do ponto de vista numérico, a presença de grupos de imigrantes e refugiados em locais específicos do país - como citado anteriormente - tem evidenciado importantes problemas, tais como: inserções precárias de trabalho, condições de vida comprometidas pela não inclusão com a realização plena de direitos, ausência 
de respeito às diferenças e à diversidade, assim como atos de racismo - principalmente em relação a imigrantes negros - colocados em evidência nas últimas décadas.

Sob outra perspectiva, já podem ser identificados alguns avanços alcançados nos processos de inclusão desses grupos, por exemplo, a contratação de agentes comunitários de Saúde, oriundos dos grupos de imigrantes, no contexto da atenção básica em saúde e também o incremento de políticas específicas para os imigrantes, tanto em âmbito local - Lei Municipal da Imigração, na cidade de São Paulo (São Paulo, 2016) - como em âmbito nacional - Lei Nacional da Migração (Brasil, 2017) -, que constituem a expressão de um importante avanço no plano legislativo direcionando à implantação de políticas inclusivas, ainda que a lei nacional tenha sido alterada por vetos presidenciais. Os desdobramentos por meio das ações derivadas a partir disso se constituem como importantes indutores ao desenvolvimento dos processos de inclusão de imigrantes trabalhadores, seus familiares e seus descendentes.

Os cuidados em saúde acabam por constituir a porta de entrada para os imigrantes nos serviços públicos, pois em algum momento haverá busca de alívio aos seus sofrimentos em contextos de serviços marcados por desafios nos processos de inclusão. Nessa perspectiva, não basta ter o cartão SUS e direito de acesso estabelecido para o atendimento como qualquer outro cidadão. Há especificidades próprias a esses grupos que provavelmente são desconhecidas dos profissionais de saúde nos diversos níveis de atenção, como também há desconhecimento dos imigrantes sobre a forma como esse cuidado é realizado. Os processos de saúde, doença, atenção e prevenção entre os diferentes grupos de imigrantes podem conter similaridades e distanciamentos com os modelos de atenção dos profissionais de saúde. As diferenças internas entre os imigrantes e refugiados de uma mesma nacionalidade acabam suprimidas pelo fato de ser de um ou outro local distante do Brasil. As diferenças dessas pessoas, explicitadas pela língua, pelo sotaque, pelas vestimentas ou por determinados costumes e comportamentos, entre outros, muitas vezes pouco dizem sobre suas cosmovisões.
Por outro lado, os profissionais de saúde também possuem poucos elementos para lidar com esse fenômeno complexo. Nossas provocações sobre a interculturalidade e seus limites buscaram trazer alguns elementos teóricos que podem contribuir para reflexão sobre as práticas no sistema de saúde e para as políticas públicas voltadas a essas populações. Nesse sentido, reiteramos os desafios da interculturalidade propostos por Menéndez (2016).

Oliveira (2000), ao problematizar a questão da identidade, utiliza o termo "(des)caminhos" para identificar uma ambiguidade, sugerindo um questionamento sobre como enxergar esse fenômeno sociocultural, tanto para o olhar do homem da rua quanto para o olhar sofisticado do cientista social. Neste texto, propusemos um caminho reflexivo de que a interpretação sobre as limitações descritas estão presentes não só entre os profissionais de saúde, mas também entre os pesquisadores que trabalham nas interfaces dos processos migratórios e das políticas e ações em saúde. A complexa teia de relações formada dentro dos serviços envolve demandas dos imigrantes, ações de trabalhadores e gestores em saúde, assim como a permanência de pesquisadores como observadores e participantes de muitas das atividades desenvolvidas dentro e fora dos serviços de saúde (Silveira et al., 2016).

Dessa forma, as iniciativas desenvolvidas abrem um amplo campo para o desenvolvimento de pesquisas empíricas e teóricas e também para a autorreflexão sobre as maneiras como lidamos com o "outro", o "imigrante" ou "refugiado", além de como nos vemos nos processos de saúde, doença e atenção. Por fim, buscamos oferecer uma contextualização da temática das migrações internacionais e da saúde dos imigrantes e refugiados. 0 indicativo do potencial de reflexão proposto aponta na direção de apresentar elementos que possam ser debatidos em distintas situações, seja na área acadêmica em suas variações disciplinares (demografia, epidemiologia, política etc.), seja no contexto das políticas e dos serviços.

\section{Referências}

AGUIAR, M. E.; MOTA, A. O programa Saúde da Família no bairro do Bom Retiro, SP, Brasil: a 
comunicação entre bolivianos e trabalhadores de saúde. Interface: Comunicação, Saúde, Educação, Botucatu, v. 18, n. 5o, p. 493-506, 2014.

BAENINGER, R. (Org.). Imigração boliviana no Brasil. Campinas: Unicamp, 2012.

BOGUS, L.; FABIANO, M. L. O Brasil como destino das migrações internacionais recentes: novas relações, possibilidades e desafios. Ponto \& Vírgula, São Paulo, n. 18, p. 126-145, 2015.

BOLETIM CEINFO. São Paulo: Prefeitura do Município de São Paulo, ano X, n. 13, dez. 2015.

BRASIL. Lei no 9.474, de 22 de julho de 1997. Define mecanismos para a implementação do Estatuto dos Refugiados de 1951, e determina outras providências. Diário Oficial [da] República Federativa do Brasil, Brasília, DF, 23 jul. 1997. Disponível em: <https://goo.gl/TtihUr>. Acesso em: 21 fev. 2018.

BRASIL. Lei $n^{0}$ 13.445, de 24 de maio de 2017. Institui a Lei de Migração. Diário Oficial da União, Brasília, DF, 25 maio 2017. Disponível em: <https://goo.gl/t8jSAA>. Acesso em: 21 fev. 2018.

CAVALCANTI, L.; OLIVEIRA, A. T.; TONHATI, T. (Org.). A inserção dos imigrantes no mercado de trabalho brasileiro. Brasília, DF: Cadernos do Observatório das Migrações Internacionais, 2015.

FASSIN, D. O sentido da saúde: antropologia das políticas da vida. In: SAILANT, F.; GENEST, S. Antropologia médica: ancoragens locais, desafios globais. Rio de Janeiro: Fiocruz, 2012. p. 375-39o.

FOSTER, N. S. O cuidado aos imigrantes bolivianos e bolivianas no contexto da atenção primária em saúde: uma aproximação etnográfica. 2017. Dissertação (Mestrado em Saúde Coletiva) - Universidade Federal de São Paulo, São Paulo, 2017.

GOLDBERG, A.; SILVEIRA, C. Social inequality, access conditions to public health care and processes of care in Bolivian immigrants in Buenos Aires and São Paulo: a comparative inquiry. Saúde e Sociedade, São Paulo, v. 22, n. 2, p. 283-297, 2013. Disponível em: <https://goo.gl/ cHS868>. Acesso em: 12 mar. 2018.
GOLDBERG, A.; SOW, P. Migrantes senegaleses en Argentina: contexto sociopolítico-laboral y vulneración de derechos. In: TEDESCO, J. C.; KLEIDERMACHER, G. (Org.). A imigração senegalesa no Brasil e na Argentina: múltiplos olhares. Porto Alegre: EST Edições, 2017. p. 117-134.

GOLDBERG, A.; MARTIN, D.; SILVEIRA, C. Por um campo específico de estudos sobre processos migratórios e de saúde na Saúde Coletiva. Interface: Comunicação, Saúde, Educação, Botucatu, v. 19, n. 53, p. 229-232, 2015.

GRANADA, D. et al. Discutir saúde e imigração no contexto atual de intensa mobilidade humana. Interface: Comunicação, Saúde, Educação, Botucatu, v. 21, n. 61, p. 285-296, 2017.

HAYDU, M. Refugiados congoleses na cidade de São Paulo: processo migratório e itinerários terapêuticos. 2017. Tese (Doutorado em Saúde Coletiva) - Universidade Estadual de São Paulo, São Paulo, 2017.

LEÃO, L. H. C. et al. Migração internacional, saúde e trabalho: uma análise sobre os haitianos em Mato Grosso, Brasil. Cadernos de Saúde Pública, Rio de Janeiro, v. 33, n. 7, p. 1-7, 2017.

MALKKI, L. Speechless emissaries: refugees, humanitarianism, and dehistoricization. Cultural Anthropology, Arlington, v. 11, p. 377-404, ago. 1996.

MAUSS, M. Sociologia e antropologia. São Paulo: Edusp, 1974.

MENÉNDEZ, E. L. Modelos de atención de los padecimientos: de exclusiones teoricas y articulaciones prácticas. Ciência e Saúde Coletiva, Rio de Janeiro, v. 8, n. 1, p. 185-208, 2003.

MENÉNDEZ, E. L. Salud intercultural: propuestas, acciones y fracasos. Ciência e Saúde Coletiva, Rio de Janeiro, v. 21, n. 1, p. 109-118, 2016.

MOTA, A.; MARINHO, M. G. S. M. C.; SILVEIRA, C. (Org.). Saúde e história de migrantes e imigrantes: direitos, instituições e circularidades. São Paulo: FMUSP, 2014. (Coleção Medicina, Saúde e História. Volume 5).

OLIVEIRA, A. T. Um panorama da migração internacional a partir do Censo Demográfico 
de 2010. REMHU: Revista Interdisciplinar da Mobilidade Humana, Brasília, DF, v. 21, n. 40, p. 195-210, 2013.

OLIVEIRA, R. C. O. Os (des)caminhos da identidade. Revista Brasileira de Ciências Sociais, São Paulo, v. 15, n. 42, p. 7-21, 2000.

PACÍFICO, A. P.; GAUDÊNCIO, M. R. B. A proteção dos deslocados ambientais no regime internacional dos refugiados. REMHU: Revista Interdisciplinar da Mobilidade Humana, Brasília, DF, v. 22, n. 43, p. 133-148, 2014.

PATARRA, N. L. Migrações internacionais de e para o Brasil contemporâneo: volumes, fluxos, significados e políticas. SP em Perspectiva, São Paulo, v. 19, n. 3, p. 23-33, 2005.

PEIRANO, M. Pecados e virtudes da antropologia: uma reação ao problema do nacionalismo metodológico. Novos Estudos Cebrap, São Paulo, n. 69, p. 49-56, jul. 2004.

RISSON, A. P. Cartografia da atenção à saúde de imigrantes haitianos residentes em Chapecó, SC. 2016. Dissertação (Mestrado em Ciências da Saúde) - Universidade Comunitária da Região de Chapecó, 2016.

RIZEK, C. A.; GEORGES, I.; SILVA, C. F. Trabalho e imigração: uma comparação Brasil-Argentina. Lua Nova, São Paulo, n. 79, p. 11-142, 2010.

SALA, G. A.; CARVALHO, J. A. M. A presença de imigrantes de países do Cone Sul no Brasil: medidas e reflexões. Revista Brasileira de Estudos de População, São Paulo, v. 25, n. 2, p. 287-304, 2008.

SANTOS, F. V. A inclusão dos migrantes internacionais nas políticas do sistema de saúde brasileiro: o caso dos haitianos no Amazonas. História, Ciências, Saúde-Manguinhos, Rio de Janeiro, v. 23, n. 2, p. 477-494, 2016.

SÃO PAULO. Secretaria Geral Parlamentar. Projeto de Lei 01-00142/2016. Institui a Política Municipal para a População Imigrante, dispõe sobre seus objetivos, princípios, diretrizes e ações prioritárias, bem como sobre o Conselho Municipal de Imigrantes. Diário Oficial da Cidade de São Paulo, São Paulo, 15 abr. 2016. Disponível em: <https:// goo.gl/DU68TX>. Acesso em: 21 fev. 2018.
SARGENT, C.; LARCHANCHÉ, S. Transnational migration and global health: the production and management of risk, illness and access to care. Annual Review of Anthropology, Palo Alto, v. 40, n. 1, p. 345-361, 2011.

SASSEN, S. As cidades na economia mundial. São Paulo: Studio Nobel, 1988.

SILVA, S. A. A migração dos símbolos: diálogo intercultural e processos identitários entre os bolivianos em São Paulo. São Paulo em Perspectiva, São Paulo, v. 19, n. 3, p. 77-83, 2005.

SILVA, S. A. Imigração e redes de acolhimento: o caso dos haitianos no Brasil. Revista Brasileira de Estudos de População, São Paulo, v. 34, n. 1, p. 99$117,2017$.

SILVEIRA, C. et al. O lugar dos trabalhadores de saúde nas pesquisas sobre processos migratórios internacionais e saúde. Cadernos de Saúde Pública, Rio de Janeiro, v. 32, n. 10, 2016. Não paginado.

SIMÕES, G. et al. Perfil demográfico e sociolaboral da migração venezuelana no Brasil: resumo executivo. Brasília, DF: Conselho Nacional de Imigração, 2017.

STEFFENS, I.; MARTINS, J. "Falta um Jorge": a saúde na política para imigrantes de São Paulo (SP). Lua Nova, São Paulo, n. 98, p. 275-299, maio/ ago. 2016.

WIMMER, A.; SCHILLER, N. G. Methodological nationalism and beyond: nation-state building, migration and the social sciences. Global Networks, Hoboken, v. 2, n. 4, p. 301-334, 2002.

ZIMMERMAN, C.; KISS, L.; HOSSAIN, M. Migration and health: a framework for 21st century policy-making. PLoS Med, San Francisco, v. 8, n. 5, 2011. Não paginado.

\section{Contribuição dos autores}

Todos os autores contribuíram na concepção do projeto, redação do manuscrito e revisão final do texto.

Recebido: $18 / 11 / 2017$

Reapresentado: 02/02/2018

Aprovado: 03/02/2018 